\title{
Kinetic and Mechanistic Aspects of the Oxidative Coupling of Methane over a Li/MgO Catalyst
}

\author{
J.A. ROOS, S.J. KORF, R.H.J. VEEHOF, J.G. VAN OMMEN and J.R.H. ROSS* \\ Facuity of Chemical Technology, University of Twente, P.O. Box 217, 7500 EA Enschede \\ (The Netherlands)
}

(Received 9 January 1989, revised manuscript received 19 March 1989)

\section{ABSTRACT}

The rate of reaction of methane with oxygen in the presence of a $\mathrm{Li}$-doped $\mathrm{MgO}$ catalyst has been studied as a function of the partial pressures of $\mathrm{CH}_{4}, \mathrm{O}_{2}$ and $\mathrm{CO}_{2}$ in a well-mixed reaction system which is practically gradientless with respect to gas-phase concentrations. It is concluded that the rate determining step involves reaction of methane adsorbed on the catalyst surface with a di-atomic oxygen species. The adsorption of oxygen is relatively weak. Carbon dioxide acts as a poison for the reaction of methane with oxygen, this probably being caused by competitive adsorption on the sites where oxygen (and possibly also methane) adsorbs.

\section{INTRODUCTION}

The oxidative coupling of methane is an emerging field of catalysis, the aim of most investigations being to develop a catalyst which is able to convert methane selectively into higher hydrocarbons, preferably ethylene. Examples of promising catalyst systems which have been studied to date are $\mathrm{Mn}_{2} \mathrm{O}_{3}$ supported on $\mathrm{SiO}_{2}[1,2]$, $\mathrm{PbO}$ supported on $\mathrm{Al}_{2} \mathrm{O}_{3}$ [3], $\mathrm{Sm}_{2} \mathrm{O}_{3}$ [4] and Li-doped $\mathrm{MgO}$ [5]; the latter system will hereafter be referred to as $\mathrm{Li} / \mathrm{MgO}$. The first of these catalyst systems was operated in a cyclic system in which methane and oxygen were fed alternatively to the catalyst; the others were investigated in a continuous operation mode in which methane and oxygen were fed simultaneously to the reactor.

A possible mechanism for the oxidative coupling of methane in the presence of a $\mathrm{Li} / \mathrm{MgO}$ catalyst has been put forward by Ito et al. [5] who, using EPR spectroscopy, detected $\mathrm{Li}^{+} \mathrm{O}^{-}$centres on the catalyst and $\mathrm{CH}_{3}$ radicals in the gas phase. Based on these two observations and also on studies of $\mathrm{Li}^{+} \mathrm{O}^{-}$centres carried out by Olson et al. [6] (using single crystals of $\mathrm{MgO}$ and $\mathrm{CaO}$ doped with $\mathrm{Li}$ ), they proposed the following reaction model:

(1) The active centres are formed by substitution of a $\mathrm{Li}^{+}$ion for $\mathrm{a}^{\mathrm{Mg}}{ }^{2}$ ion in the $\mathrm{MgO}$ matrix, creating an oxygen vacancy. Gaseous oxygen molecules 
react with this vacancy, resulting in $\mathrm{O}^{2-}$ ions and positive holes. $\mathrm{A}^{+} \mathrm{Li}^{-}$ centre is produced by a hole being trapped at $\mathrm{O}^{2-}$ ions which are adjacent to $\mathrm{Li}^{+}$ions:

$2 \mathrm{Li}^{+} \mathrm{O}^{2}+\mathrm{L}+1 / 2 \mathrm{O}_{2} \leftrightarrow 2 \mathrm{Li}^{+} \mathrm{O}^{-}+\mathrm{O}^{2-}$

where $\square$ denotes an oxygen vacancy.

(ii) It is suggested that the $\mathrm{O}^{-}$ion is then capable of abstracting a hydrogen atom from the methane, resulting in the formation of a $\mathrm{CH}_{3}$ radical and a reduced active site:

$\mathrm{Li}^{+} \mathrm{O}^{-}+\mathrm{CH}_{4} \rightarrow \mathrm{Li}^{+} \mathrm{OH}^{-}+\mathrm{CH}_{3}$

The re-oxidation of the active site is thought to proceed by the following scheme:

$2 \mathrm{Li}^{+} \mathrm{OH}^{-} \rightarrow \mathrm{Li}^{+} \mathrm{O}^{2-}+\mathrm{Li}^{+} \square+\mathrm{H}_{2} \mathrm{O}$

$\mathrm{Li}^{+} \mathrm{O}^{2-}+\mathrm{Li}^{+} \square+1 / 2 \mathrm{O}_{2} \rightarrow 2 \mathrm{Li}^{+} \mathrm{O}^{-}$

(iii) Ethane is formed by the coupling of two $\mathrm{CH}_{3}$ radicals, in the gas phase near the surface:

$2 \mathrm{CH}_{3} \rightarrow \mathrm{C}_{2} \mathrm{H}_{6}$

(iv) Ethylene is subsequently produced from the ethane by oxidative dehydrogenation by surface $\mathrm{O}^{-}$ions. $(\mathrm{v})$ The formation of total oxidation products, $\mathrm{CO}$ and $\mathrm{CO}_{2}$, proceeds through the oxidation of the $\mathrm{CH}_{3}$ radicals by a surface $\mathrm{O}^{2-}$ ion or a gas phase $\mathrm{O}_{2}$ molecule, this occurring parallel to the formation of $\mathrm{C}_{2} \mathrm{H}_{6}$.

Rased on the observation that $\mathrm{O}^{-}$ions on $\mathrm{MoO}_{3} / \mathrm{SiO}_{2}$ are capable of producing $\mathrm{CH}_{3}$ radicals from $\mathrm{CH}_{4}$ at temperatures as low as $77 \mathrm{~K}$, it was proposed that the rate determining step is not the activation of $\mathrm{CH}_{4}$ but the dehydroxylation or re-oxidation reaction (reaction 3 or 4 ).

The above reaction model as proposed by Ito et al. [5] is thus in essence an oxidation-reduction model, involving a change in the (formal) valency of the surface oxygen ion: from $\mathrm{O}^{-}$in the oxidised state of the active site to $\mathrm{O}^{2-}$ (i.e. the oxygen in the $\mathrm{OH}^{-}$group ) in the reduced state, with the re-oxidation of the active site being the rate-determining step. We believe, however, that their hypothesis regarding the rate limiting step is in contradiction with another observation made by Ito et al., namely a positive reaction order (ca. 0.4 ) of $\mathrm{CH}_{4}$. We think therefore that the rate-determining step must be a reaction involving $\mathrm{CH}_{4}$. This is discussed further below in relation to our own results.

Additional evidence for the hypothesis regarding the gas phase hydrocarbon building reactions and the involvement of radicals as postulated in the reaction mechanism of Ito et al. has been obtained by Sofranko et al. [1]: basing their arguments on a comparison of the hydrocarbon product distribution in cyclic experiments in the presence of many different catalysts with that of an empty tube, they concluded that hydrocarbon building reactions take place in the gas 
phase, starting from the $\mathrm{CH}_{3}$ radical. Paneth lead-mirror experiments confirmed that radicals may be formed from $\mathrm{CH}_{4}$.

Otsuka et al. [7] have proposed a different mechanism for the oxidative coupling reaction over a $\mathrm{Sm}_{2} \mathrm{O}_{3}$ catalyst, this being based on kinetic measurements. They found that the rate of reaction as a function of the partial pressures of $\mathrm{CH}_{4}$ and $\mathrm{O}_{2}$ could be described by a mechanism involving adsorption of $\mathrm{CH}_{4}$ and $\mathrm{O}_{2}$ on different sites (reaction 6 and 7 ). According to their results, an adsorbed di-atomic oxygen species is involved in the formation of a $\mathrm{CH}_{3}$ radical from an adsorbed $\mathrm{CH}_{4}$ molecule, this reaction being the rate limiting step ( reaction 8):

$\mathrm{CH}_{4}(\mathrm{~g}) \leftrightarrow \mathrm{CH}_{4}(\mathrm{a})$

$\mathrm{O}_{2}(\mathrm{~g}) \leftrightarrow \mathrm{O}_{2}(\mathrm{a})$

$\mathrm{CH}_{4}(\mathrm{a})+\mathrm{O}_{2}(\mathrm{a}) \rightarrow \mathrm{CH}_{3}+\mathrm{HO}_{2}$

Higher hydrocarbons and carbon oxides are subsequently formed from the $\mathrm{CH}_{3}$ radical by reactions either on the surface or in the gas phase near the surface of the catalyst

$2 \mathrm{CH}_{3} \rightarrow \mathrm{C}_{2} \mathrm{H}_{6}$

$\mathrm{CH}_{3}+\mathrm{O}_{2} \rightarrow \mathrm{CH}_{3} \mathrm{O}_{2} \rightarrow \rightarrow \mathrm{CO}, \mathrm{CO}_{2}$

Based on the observation that the peroxides of $\mathrm{Na}, \mathrm{Ba}$ and $\mathrm{Sr}$ are very active for oxidative coupling of methane, Otsuka et al. proposed that the di-atomic oxygen species is a peroxide ion $[7,8]$.

This paper is one of a series of interrelated papers in which we describe experiments aimed at clarifying the reaction mechanism and the network of reactions taking place in the oxidative coupling of methane over $\mathrm{Li} / \mathrm{MgO}$ and doped $\mathrm{Sm}_{2} \mathrm{O}_{3}$ catalysts. In the first publication of this series [9], we have shown that the further oxidation of the $\mathrm{C}_{2}$ products (producing $\mathrm{CO}$ and $\mathrm{CO}_{2}$ ) plays an important role in the reaction network of the oxidative coupling of methane over $\mathrm{Li} / \mathrm{MgO}$ and $\mathrm{Ca} / \mathrm{Sm}_{2} \mathrm{O}_{3}$ catalysts. In a following publication we shall show that the non selective products, $\mathrm{CO}$ and $\mathrm{CO}_{2}$, are produced solely from $\mathrm{C}_{2} \mathrm{H}_{4}$ if a $\mathrm{Li} / \mathrm{MgO}$ sample is used as a catalyst at a reaction temperature of $720^{\circ} \mathrm{C} \mathrm{[10]}$. This article gives the results of kinetic experiments carried out with a $\mathrm{Li} / \mathrm{MgO}$ catalyst with the aim of getting a better understanding of the reaction mechanism. The rate of the oxidative coupling reaction was therefore studied as a function of the partial pressures of $\mathrm{O}_{2}, \mathrm{CH}_{4}$ and $\mathrm{CO}_{2}$, the partial pressure of water being kept constant in all experiments. The effect carbon dioxide and water has been taken into account because carbon dioxide reversibly poisons (and stabilizes) the active sites of the catalyst and because water has a detrimental effect on catalyst activity, as has been shown in previous publications $[11,12]$. 


\section{EXPERIMENTAL}

\section{Reaction systems}

The reaction system (Fig. 1) used for the kinetic experiments behaves as a gradientless reactor with respect to gas phase concentrations, this being achieved by external recirculation of the product gas using a membrane pump (P). A recirculation ratio (i.e. the ratio of the recycle flow to the net flow through the system) of 30 is used [9]. Water vapour is condensed out of the reactor-effluent directly after the reactor using a cold trap (C) maintained at $0 \circ \mathrm{C}$. A fresh feed-gas mixture with a flow-rate of $0.13 \mathrm{~cm}^{3} \mathrm{~s}^{-1}$ (STP) is added to the recycle loop. The effluent of the recycle system leaves the loop at one of two positions, before or after the reactor; these exit flows may be sampled and comparison of the composition allows verification of the absence of concentration gradients across the catalyst bed. The gas composition is analysed by gas chromatography. The reactor tube (quartz, $6 \mathrm{~mm}$ I.D.) passes through two ovens, each $10 \mathrm{~cm}$ long: the first of these is maintained at a temperature of $500^{\circ} \mathrm{C}$ to preheat the gas and the second is maintained at the desired reaction temperature. The catalyst bed ( $500 \mathrm{mg}$ of catalyst, particle size $0.1-0.3 \mathrm{~mm}$ ) is placed in the reactor tube at the centre of the second oven and a thermocouple (in a quartz capillary) is located in the middle of the bed. A maximum temperature deviation of $4^{\circ} \mathrm{C}$ from the average temperature in the catalyst bed has been observed under normal reaction conditions. The rates of flow of the effluent from the system are measured using a soap-bubble meter.

\section{Catalyst preparation}

The $\mathrm{Li} / \mathrm{MgO}$ catalyst used in this work was prepared by wet impregnation of $\mathrm{Mg}(\mathrm{OH})_{2}$ (Merck, p.a.) with an aqueous solution of LiOH (Merck, p.a.).

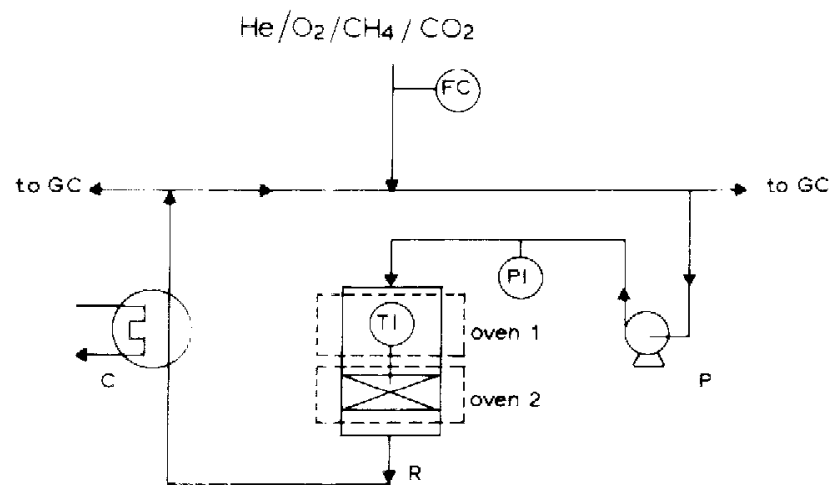

Fig. 1. Schematic representation of the recycle reactor: R, reactor; FC, flow controllers; PI, pressure indicator; TI, temperature indicator; P, pump; C, cold trap. 
Carbon dioxide was passed through the solution during evaporation of the excess water. After the evaporation step, the resultant material was dried at $140^{\circ} \mathrm{C}$ overnight and calcined at $850^{\circ} \mathrm{C}$ for $6 \mathrm{~h}$. The catalyst particles were crushed and sieved to a particle size of $0.1-0.3 \mathrm{~mm}$. Analysis showed that the material contained $2.8 \mathrm{wt} . \% \mathrm{Li}$ and $8.2 \mathrm{wt} . \% \mathrm{CO}_{2}$. After use, the B.E.T. area of the catalyst (measured using argon adsorption) appeared to be smaller than 1 $\mathrm{m}^{2} \mathrm{~g}^{-1}$. Full details of the preparation are given elsewhere [12].

\section{RESULTS AND DISCUSSION}

The effect of variation of $P_{\mathrm{O}_{2}}$ and $P_{\mathrm{CH}_{4}}$

Fig, 2 shows the rate of reaction of methane as a function of the partial pressure of oxygen, the partial pressures of methane and carbon dioxide being kept constant at $58( \pm 1) \mathrm{kPa}$ and $5.2( \pm 0.1) \mathrm{kPa}$ respectively. The reaction temperature was chosen to be $720^{\circ} \mathrm{C}$, as blank reactor tests (with a bed of quartz particles replacing the catalyst bed) showed that negligible conversions of methane, ethane or ethylene occurred in the presence of oxygen at this temperature [9]. It follows from Fig. 2 that the reaction rate of methane is directly proportional to the partial pressure of oxygen (i.e. that the reaction is first order in $P_{\mathrm{O}_{2}}$ ).

The dependence of the reaction rate on the partial pressure of methane is shown in Fig. 3. In these experiments, the partial pressures of oxygen and carbon dioxide were kept constant at $4.5( \pm 0.2) \mathrm{kPa}$ and $4.7( \pm 0.3) \mathrm{kPa}$ respectively. The temperature in the catalyst bed was again kept at $720^{\circ} \mathrm{C}$. At lower values of $P_{\mathrm{CH}_{4}}$, the rate of reaction increases almost linearly with $P_{\mathrm{CH}_{4}}$ but the rate begins to level off at higher values of $P_{\mathrm{CH}_{4}}$; the fact that this "saturation effect" is observed at higher values of $P_{\mathrm{CH}_{4}}$ is indicative of a mecha-

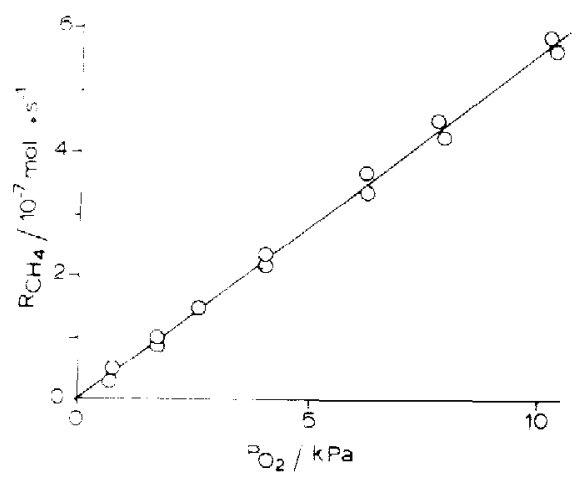

Fig. 2. The rate of reaction of $\mathrm{CH}_{4}$ as function of the partial pressure of $\mathrm{O}_{2} ; T=720^{\circ} \mathrm{C}, P_{\mathrm{CH}_{4}}=58$ $( \pm 1) \mathrm{k} \mathrm{Pa} P_{\mathrm{CO}}=5.2( \pm 0.1) \mathrm{kPa}$. 


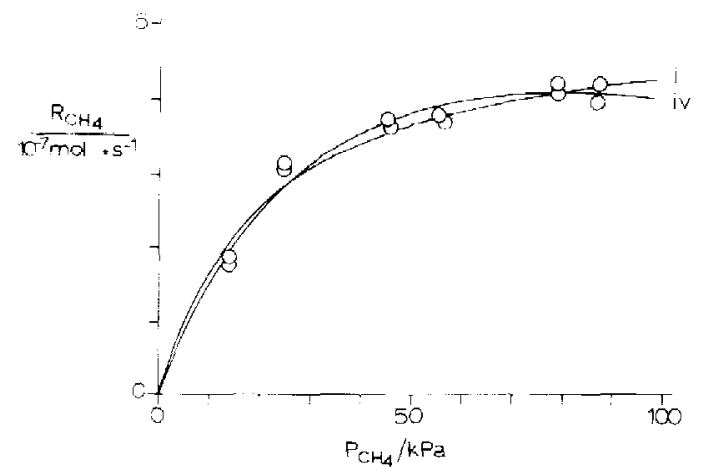

Fig. 3. The rate of reaction of $\mathrm{CH}_{4}$ as function of the partial pressure of $\mathrm{CH}_{4} ; T=720^{\circ} \mathrm{C}, \mathrm{P}_{\mathrm{O}_{2}}=4.5$ $( \pm 0.2) \mathrm{kPa}, P_{(\mathrm{O}}=4.7( \pm 0.3) \mathrm{kPa}$; models (i) and (iv), see below.

nism involving equilibrium adsorption of the methane on the surface and a rate limiting reaction step involving reaction of the adsorbed methane species. It therefore excludes the possibility of a mechanism involving reaction of methane directly from the gas phase.

The result of Fig. 2, a first order dependance on $P_{\mathrm{O}_{2}}$ (for the investigated interval of oxygen partial pressure, $P_{\mathrm{O}_{2}}<11 \mathrm{kPa}$ ) can be explained in two ways: (i) the adsorption of oxygen or the re-oxidation of the active sites of the catalyst is rate limiting; or (ii) a di-atomic oxygen species is involved in the (rate limiting) reaction with $\mathrm{CH}_{4}$. (If oxygen dissociation took place and a monoatomic oxygen species were thus involved, the order in $P_{\mathrm{O}_{2}}$ would be expected to be 0.5 ). If situation (i) were the case, the reaction rate would be independent of the partial pressure of $\mathrm{CH}_{4}$; the results of Fig. 3 show that this is not the case. We thus conclude that explanation (ii) is applicable (i.e. that a di-atomic oxygen species is involved in the rate limiting reaction step) and we suggest that the following sequence of events occurs:

$\mathrm{O}_{2}(\mathrm{~g})+\mathrm{S}_{1} \leftrightarrow \mathrm{O}_{2}(\mathrm{a})$

$\mathrm{CH}_{4}(\mathrm{~g})+\mathrm{S}_{2} \leftrightarrow \mathrm{CH}_{4}(\mathrm{a})$

$\mathrm{CH}_{4}(\mathrm{a})+\mathrm{O}_{2}(\mathrm{a}) \rightarrow \mathrm{CH}_{3}+\mathrm{HO}_{2}$

where $S_{1}$ and $S_{2}$ represent adsorption sites. Reactions 11 and 12 represent equilibrium adsorption of the di-atomic oxygen species and methane respectively; these steps are followed by reaction 13 , the rate limiting reaction step involving adsorbed methane and oxygen molecules. This step is equivalent to the initiation reaction step in hydrocarbon oxidation reactions occurring in the gas phase $[13,14]$. Independent evidence for a rate limiting step involving the activation of $\mathrm{CH}_{4}$ (as e.g. in reaction 13) is given by Cant et al. [15]; by comparison of the rate of reaction of $\mathrm{CH}_{4}$ with that of $\mathrm{CD}_{4}$ over a $\mathrm{Li} / \mathrm{MgO}$ catalyst 
at $750^{\circ} \mathrm{C}$, they showed that the $\mathrm{C}-\mathrm{H}$ bond breaking reaction is rate-limiting under these conditions. Reaction 13 will be discussed in detail below.

Assuming that the mechanism represented by eqns. (11)-(13) holds, the rate of reaction of methane, $R_{\mathrm{CH}_{4}}$, is given by step (13) and may be expressed as follows:

$R_{\mathrm{CH}_{4}}=k_{r} \cdot \theta_{\mathrm{O}_{2}} \cdot \theta_{\mathrm{CH}_{4}}$

where $\theta_{\mathrm{O}_{2}}$ and $\theta_{\mathrm{CH}_{4}}$ are the coverages of $\mathrm{O}_{2}$ and $\mathrm{CH}_{4}$ respectively and $k_{\mathrm{r}}$ is the rate constant of the reaction. In such a mechanism, two models may be distinguished:

(i) $\mathrm{CH}_{4}$ and $\mathrm{O}_{2}$ adsorb on different sites; if we assume that the adsorption of $\mathrm{O}_{2}$ and $\mathrm{CH}_{4}$ may be described by a Langmuir isotherm, this results in the following equations for the coverage of the active sites by $\mathrm{CH}_{4}$ and $\mathrm{O}_{2}$ species:

$\theta_{\mathrm{O}_{2}}=b_{\mathrm{O}_{2}} \cdot P_{\mathrm{O}_{2}} /\left(1+b_{\mathrm{O}_{2}} \cdot P_{\mathrm{O}_{2}}\right)$

$\theta_{\mathrm{CH}_{4}}=b_{\mathrm{CH}_{4}} \cdot P_{\mathrm{CH}_{4}} /\left(1+b_{\mathrm{CH}_{4}} \cdot P_{\mathrm{CH}_{4}}\right)$

where $b_{\bigcirc_{2}}$ and $b_{\mathrm{CH}_{4}}$ are the corresponding adsorption coefficients of $\mathrm{O}_{2}$ and $\mathrm{CH}_{4}$ respectively.

(ii) $\mathrm{CH}_{4}$ and $\mathrm{O}_{2}$ adsorb on the same site $\left(\mathrm{S}_{1}=\mathrm{S}_{2}\right)$. In this case the following expressions are obtained:

$\theta_{\mathrm{O}_{2}}=b_{\mathrm{O}_{2}} \cdot P_{\mathrm{O}_{2}} /\left(1+b_{\mathrm{O}_{2}} \cdot P_{\mathrm{O}_{2}}+b_{\mathrm{CH}_{4}} \cdot P_{\mathrm{CH}_{4}}\right)$

$\theta_{\mathrm{CH}_{4}}=b_{\mathrm{CH}_{4}} \cdot P_{\mathrm{CH}_{4}} /\left(1+b_{\mathrm{O}_{2}} \cdot P_{\mathrm{O}_{2}}+b_{\mathrm{CH}_{4}} \cdot P_{\mathrm{CH}_{4}}\right)$

It has been shown above that the reaction is strictly first order in $P_{\mathrm{O}_{2}}$ for $P_{\mathrm{O}_{2}}<11 \mathrm{kPa}$. The term $b_{\mathrm{O}_{2}} \cdot P_{\mathrm{O}_{2}}$ in the denominator of eqns. (b), (d) and (e) may therefore be neglected under these conditions. This implies that the adsorption of oxygen is relatively weak. The final expressions for $R_{\mathrm{CH}_{4}}$, according to models (i) and (ii) are given by eqns. (f) and (g) respectively:

$$
\begin{aligned}
& R_{\mathrm{CH}_{4}}=k_{\mathrm{R}} \cdot b_{\mathrm{O}_{2}} \cdot P_{\mathrm{O}_{2}} \cdot b_{\mathrm{CH}_{4}} \cdot P_{\mathrm{CH}_{4}} /\left(1+b_{\mathrm{CH}_{4}} \cdot P_{\mathrm{CH}_{4}}\right) \\
& R_{\mathrm{CH}_{4}}=k_{\mathrm{R}} \cdot b_{\mathrm{O}_{2}} \cdot P_{\mathrm{O}_{2}} \cdot b_{\mathrm{CH}_{4}} \cdot P_{\mathrm{CH}_{4}} /\left(1+b_{\mathrm{CH}_{4}} \cdot P_{\mathrm{CH}_{4}}\right)^{2}
\end{aligned}
$$

In order to try to determine which, if either, of the two models is applicable, a graphical method may be used. This involves linearization of the rate equations, following a procedure similar to that used by Otsuka and Jinno [7]. If the first model of the adsorption of oxygen and methane on different sites (eqn. f) is correct, a straight line should be obtained when the value of the partial pressure of methane divided by the reaction rate $\left(P_{\mathrm{CH}_{4}} / R_{\mathrm{CH}_{4}}\right)$ is plotted against $P_{\mathrm{CH}_{4}}$; such a plot is shown in Fig. 4. If the model of adsorption on one site (eqn. g) is applicable, a plot of $\left(P_{\mathrm{CH}_{4}} / R_{\mathrm{CH}_{4}}\right)^{0.5}$ versus $P_{\mathrm{CH}_{4}}$ should give a straight 


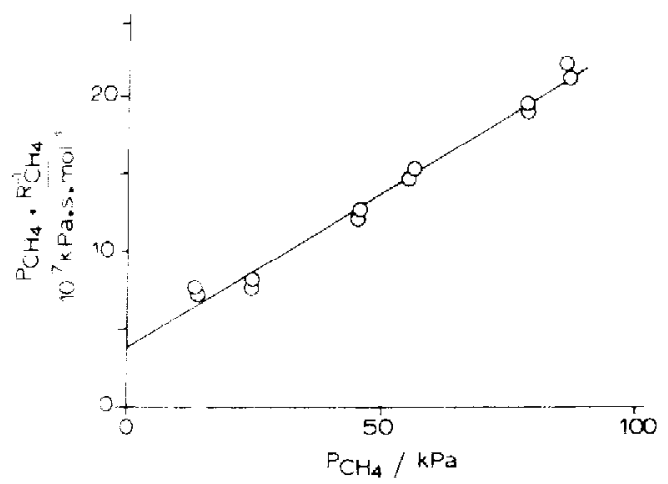

Fig 4. $P_{\mathrm{CH}_{4}} / R_{\mathrm{CH}_{4}}$ as a function of $P_{\mathrm{CH}_{4}}$; linearization of eqn. (f).

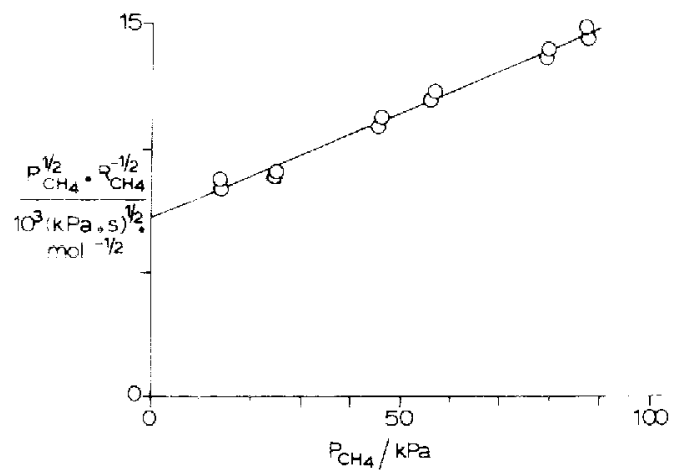

Fig 5. $\left(P_{\mathrm{CH}_{i}} / R_{\mathrm{CH}_{4}}\right)^{0 . \overline{5}}$ as a function of $P_{\mathrm{CH}_{4}}$; linearization of eqn. $(\mathrm{g})$.

line; see Fig. 5. As can be seen from Figs. 4 and 5, both plots give straight lines. It is therefore impossible to discriminate between the two models on the basis of these measurements alone.

The effect of the variation of $P_{C O}$

Fig. 6 shows the effect on the rate of reaction of a variation of the partial pressure of $\mathrm{CO}_{2}$ in an experiment in which the partial pressures of oxygen and methane were kept constant at $6.6( \pm 0.2) \mathrm{kPa}$ and $56( \pm 1) \mathrm{kPa}$ respectively. The reaction temperature was again $720^{\circ} \mathrm{C}$. The results of Fig. 6 clearly show that $\mathrm{CO}_{2}$ acts as a poison for the reaction; this poisoning probably arises from competitive adsorption of the $\mathrm{CO}_{2}$ with the methane and/or the oxygen.

Four different situations may now be considered in relation to the two models discussed above: (i.a) A two-site model involving competitive adsorption of 


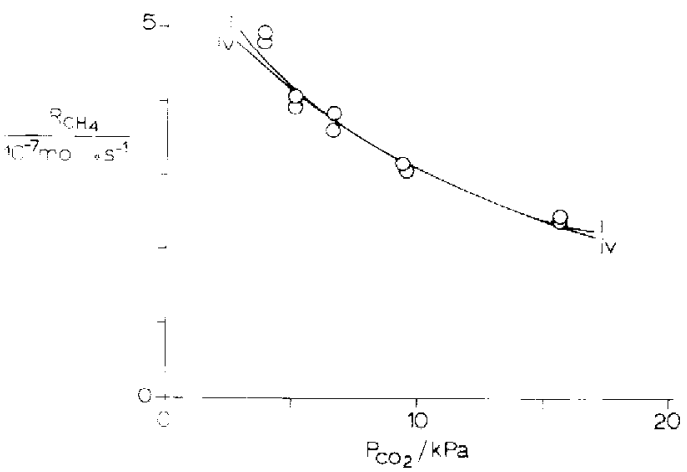

Fig. 6. The rate of reaction of $\mathrm{CH}_{4}$ as function of the partial pressure of $\mathrm{CO}_{2} ; T=720^{\circ} \mathrm{C}, P_{\mathrm{O}_{2}}=6.6$ $\pm 0.2) \mathrm{kPa}, P_{\mathrm{CH}}=56( \pm 1) \mathrm{kPa}$; models (i) and (iv), see text.

$\mathrm{CO}_{2}$ on the site on which $\mathrm{O}_{2}$ adsorbs and adsorption of $\mathrm{CH}_{4}$ on another type of site In this situation, assuming that $b_{\mathrm{O}_{2}} \cdot P_{\mathrm{O}_{2}}$ is negligible, eqn. (b) must thus be re-written as:

$\theta_{\mathrm{O}_{2}}=b_{\mathrm{O}_{2}} \cdot P_{\mathrm{O}_{2}} /\left(1+b_{\mathrm{CO}_{2}} \cdot P_{\mathrm{CO}_{2}}\right)$

where $b_{\mathrm{CO}_{2}}$ is the adsorption constant for $\mathrm{CO}_{2}$. If the methane coverage, $\theta_{\mathrm{CH}_{4}}$, is again given by eqn. (c), the all-over rate is given by:

$R_{\mathrm{CH}_{4}}=k_{\mathrm{r}} \cdot b_{41_{2}} \cdot P_{\mathrm{O}_{2}} \cdot b_{\mathrm{CH}_{4}} \cdot P_{\mathrm{CH}_{4}} /\left(\left(1+b_{\mathrm{CO}_{2}} \cdot P_{\mathrm{CO}_{2}}\right) \cdot\left(1+b_{\mathrm{CH}_{4}} \cdot P_{\mathrm{CH}_{4}}\right)\right)$

(i.b) A two-site model with competitive adsorption of $\mathrm{CO}_{2}$ on the sites on which $\mathrm{CH}_{4}$ adsorbs and weak adsorption of $\mathrm{O}_{2}$ on another type of site. Eqn. (c) may thus be re written as:

$\theta_{\mathrm{CH}_{4}}=b_{\mathrm{CH}_{4}} \cdot P_{\mathrm{CH}_{4}} /\left(1+b_{\mathrm{CH}_{4}} \cdot P_{\mathrm{CH}_{4}}+b_{\mathrm{CO}_{2}} \cdot P_{\mathrm{CO}_{2}}\right)$

When the oxygen coverage, $\theta_{\mathrm{O}_{2}}$, is described by eqn. (b), the all-over rate is given by:

$R_{\mathrm{CH} .}=k_{\mathrm{r}} \cdot b_{\mathrm{O}_{2}} \cdot P_{\mathrm{O}_{2}} \cdot b_{\mathrm{CH}_{4}} \cdot P_{\mathrm{CH}_{4}} /\left(1+b_{\mathrm{CH}_{4}} \cdot P_{\mathrm{CH}_{4}}+b_{\mathrm{CO}_{2}} \cdot P_{\mathrm{CO}_{2}}\right)$

(i.c) A two site model with competitive $\mathrm{CO}_{2}$ adsorption on both the sites. In this case, both eqn. $(h)$ and $(k)$ are used to given the rate expression:

$$
\begin{aligned}
R_{\mathrm{CH}_{4}}=k_{\mathrm{T}} \cdot b_{\mathrm{O}_{2}} \cdot P_{\mathrm{O}_{2}} \cdot b_{\mathrm{CH}_{4}} \cdot P_{\mathrm{CH}_{4}} /\left(\left(1+b_{\mathrm{CO}_{2}} \cdot P_{\mathrm{CO}_{2}}\right) \cdot\right. \\
\left(1+b_{\mathrm{CH}_{4}} \cdot P_{\mathrm{CH}_{4}}+b_{\mathrm{CO}_{2}}^{\prime \prime} \cdot P_{\mathrm{CO}_{2}}\right)
\end{aligned}
$$

(ii) A one-site model with competitive adsorption of $\mathrm{CO}_{2}$ on the site on which both $\mathrm{CH}_{4}$ and $\mathrm{O}_{2}$ adsorb. In this case, the term $b_{\mathrm{CO}_{2}} \cdot P_{\mathrm{CO}_{2}}$ should be added to the denominator of eqns. (d) and (e) with the result:

$R_{\mathrm{CH}_{4}}=k_{\mathrm{r}} \cdot b_{\mathrm{O}_{2}} \cdot P_{\mathrm{O}_{2}} \cdot b_{\mathrm{CH}_{4}} \cdot P_{\mathrm{CH}_{4}} /\left(1+b_{\mathrm{CH}_{4}} \cdot P_{\mathrm{CH}_{4}}+b_{\mathrm{CO}_{2}} \cdot P_{\mathrm{CO}_{2}}\right)^{2}$ 
If model (i.a) (eqn. j) or (i.b) (eqn. 1) is applicable, a plot of the reciprocal value of the reaction rate $\left(1 / R_{\mathrm{CH}_{4}}\right)$ against $P_{\mathrm{CO}_{2}}$ should give a straight line; this is found to be the case (result not shown). However, by analogy with the results described above for the variation of $P_{\mathrm{CH}_{4}}$, linearization of rate equation ( $\mathrm{n}$ ) for the one site model (ii) also gives a good correlation. Rate equation $(\mathrm{m})$ of model (i.c) cannot be linearized and so a graphical evaluation of this possibility is impossible. It is therefore clear that graphical methods cannot be used to distinguish between the models. A distinction may, however, be achieved by calculating the values of the adsorption constants for each of the models. For models (i.a), (i.b) and (ii), this could be achieved by calculating the ratio of the slope to the intercept of the linearized versions of eqns. (j), (l) and $(n)$ in a manner analogous to the procedure used by Otsuka and Jinno [7]. The $b$ values calculated for model (i.b) were negative and so this model may be excluded. Although rate equation $(\mathrm{m})$ could not be linearized, as discussed above, it could be shown mathematically that this model also resulted in negative $b$ values and thus that model (i.c) could also be excluded. As the adsorption constants for models (i.a) and (ii) were positive and were therefore of significance, it can be concluded that one of these models is appropriate.

The adsorption constants for $\mathrm{CH}_{4}\left(b_{\mathrm{CH}_{4}}\right)$ resulting from eqns. (j) and (n) are given in Table 1 . The independent values of $b_{\mathrm{O}_{2}}$ and $k_{\mathrm{r}}$ could not be calculated; however, the product $k_{\mathrm{r}} \cdot b_{\mathrm{O}_{2}}$ could be calculated from all three series of experiments (i.e. for the variation of $P_{\mathrm{CH}_{4}}, P_{\mathrm{CO}_{2}}$ and $P_{\mathrm{O}_{2}}$ ) for both models and the results are also given in Table 1 .

The data of Table 1 show that the value of the adsorption constant $b_{\mathrm{CO}_{2}}$ is relatively large compared to that of $b_{\mathrm{CH}_{4}}$ in both models. This result is consistent with results obtained earlier regarding the strong poisoning effect on the conversion of methane of the addition of small amounts of carbon dioxide to the feed $[11,12]$. The small differences in the values of $k_{\mathrm{r}} \cdot b_{\mathrm{O}_{2}}$ shown in Table 1 calculated for both models from different sets of data are not significant; they could, for example, be caused by a slow increase of catalyst activity which was observed during the experiments, or by different degrees of competitive ad-

\section{TABLE 1}

Kinetic parameters caluclated for models (i.a) and (ii)

\begin{tabular}{llllll}
\hline Model & $b_{\mathrm{CH}_{4}}{ }^{a}$ & $k_{\mathrm{r}} \cdot b_{\mathrm{Og}_{2}}{ }^{b}$ & $b_{\mathrm{CO}_{2}{ }^{a}}$ & $k_{\mathrm{r}} \cdot b_{\mathrm{O}_{2}}{ }^{b}$ & $k_{\mathrm{r}} \cdot b_{\mathrm{O}_{2}}{ }^{b}$ \\
\hline (i.a) & 0.052 & 1.7 & 0.11 & 1.3 & 1.2 \\
(ii) & 0.016 & 4.8 & 0.07 & 3.6 & 3.1 \\
\hline
\end{tabular}

${ }^{a}$ Units of $b_{\mathrm{CH}_{4}}$ and $b_{\mathrm{CO}_{2}}: \mathrm{kPa}^{-1}$.

"Unit of $k_{\mathrm{r}} \cdot b_{\mathrm{O}_{2}}: 10^{-7} \mathrm{~mol} \cdot(\mathrm{s} \cdot \mathrm{kPa})^{-1}$. The values of $k_{\mathrm{r}} \cdot b_{\mathrm{O}_{2}}$ given in the third column are caluclated from the series of experiments in which $P_{\mathrm{CH}_{4}}$ was varied, those of the fifth and sixth columns from those in which $P_{\mathrm{CO}_{2}}$ and $P_{\mathrm{O}_{2}}$ were varied respectively. 
sorption of the other products (e.g. $\mathrm{C}_{2} \mathrm{H}_{6}$ or $\mathrm{C}_{2} \mathrm{H}_{4}$ ) in the different experiments, a factor not taken into account in the model.

Values of $R_{\mathrm{CH}_{4}}$ as a function of $P_{\mathrm{CH}_{4}}$ or $P_{\mathrm{CO}_{2}}$ were calculated using both eqns. (j) and ( $\mathrm{n}$ ) by substitution of the appropriate values of $k_{\mathrm{r}} \cdot b_{\mathrm{O}_{2}}, b_{\mathrm{CH}_{4}}, b_{\mathrm{CO}_{2}}$ given in Table 1 and the appropriate partial pressures of $\mathrm{CH}_{4}, \mathrm{O}_{2}$ and $\mathrm{CO}_{2}$. The resulting curves are shown in Figs. 3 and 6 together with the experimental data. It can be concluded that both models (i.a) and (ii) give an equally good correlation with the experimental data and that either a two-site model with competition of $\mathrm{CO}_{2}$ for the $\mathrm{O}_{2}$ adsorption site or a one-site model with $\mathrm{CO}_{2}$ competition with both adsorbing reactants may hold.

\section{A possible reaction mechanism}

In a previous publication [12], we gave a model for the formation of the active sites on the surface of $\mathrm{ai} / \mathrm{MgO}$ catalyst; this was based on experiments showing a poisoning effect of the addition of $\mathrm{CO}_{2}$ to the reaction mixture, as well as a beneficial effect on catalyst performance of the incorporation of carbonate in the catalyst during catalyst preparation. The formation of the active site was thought to involve the decomposition of surface lithium carbonate in the presence of gas-phase oxygen, possibly by adsorption of oxygen on the site resulting from the loss of $\mathrm{CO}_{2}$. It was assumed that this process is reversible; $\mathrm{CO}_{2}$ may re-adsorb on the surface, forming the (inactive) surface carbonate and resulting in a poisoning of the catalyst. The kinetic evaluations given above strongly support these ideas: both of the models (i.a) and (ii) are based on competitive adsorption of $\mathrm{CO}_{2}$ and $\mathrm{O}_{2}$. The $\mathrm{CH}_{4}$ molecule may be adsorbed on a surface site (of which the nature is yet unknown), adjacent to the site for adsorption of $\mathrm{O}_{2}$ [model (i.a)] or on the same site [model (ii)].

The observed first order in oxygen and the positive order in methane indicates that the rate limiting reaction step involves activation of adsorbed methane by a weakly bonded di-atomic oxygen species: a hydrogen atom is abstracted from the adsorbed $\mathrm{CH}_{4}$ molecule, forming $\mathrm{CH}_{3}$ and $\mathrm{HO}_{2}$ radicals according to reaction 13 (see above).

$\mathrm{CH}_{4}(\mathrm{a})+\mathrm{O}_{2}(\mathrm{a}) \rightarrow \mathrm{CH}_{3}(\mathrm{~g})+\mathrm{HO}_{2}(\mathrm{~g})$

This reaction is analogous to the process of methane activation in the gas phase (involving interaction of gas-phase molecules as opposed to adsorbed molecules in a process involving catalytic activation) [13,14]. The $\mathrm{CH}_{3}$ and $\mathrm{HO}_{2}$ radicals formed on the catalyst surface probably desorb to the gas phase, as proposed by Ito et al. [5] with respect to the $\mathrm{CH}_{3}$ radicals; however, we cannot at present exclude the possibility that one or both of these species reacts further while it is adsorbed on the catalyst surface. We assume that gas-phase reactions of these radicals predominate.

In the case of the gas-phase oxidation of $\mathrm{CH}_{4}$ at high temperature, the $\mathrm{HO}_{2}$ 
radical may react with methane to form a second $\mathrm{CH}_{3}$ radical and a hydrogen peroxide molecule, $\mathrm{H}_{2} \mathrm{O}_{2}$ [14]:

$\mathrm{HO}_{2}+\mathrm{CH}_{4} \rightarrow \mathrm{CH}_{3}+\mathrm{H}_{2} \mathrm{O}_{2}$

The $\mathrm{H}_{2} \mathrm{O}_{2}$ can decompose at these temperatures to form two $\mathrm{OH}$ radicals:

$\mathrm{H}_{2} \mathrm{O}_{2} \rightarrow 2 \mathrm{OH}$

These $\mathrm{OH}$ radicals may then continue the reaction chain:

$\mathrm{CH}_{4}+\mathrm{OH} \rightarrow \mathrm{CH}_{3}+\mathrm{H}_{2} \mathrm{O}$

In the gas-phase activation process, reactions (14) and (16) are fast compared to the initiation reaction involving molecular oxygen. Two $\mathrm{CH}_{3}$ radicals may combine to form $\mathrm{C}_{2} \mathrm{H}_{6}$ according to reaction 9:

$2 \mathrm{CH}_{3} \rightarrow \mathrm{C}_{2} \mathrm{H}_{6}$

The overall reaction resulting from a combination of reactions (13), (14)(16) and (9) is thus given by:

$4 \mathrm{CH}_{4}+\mathrm{O}_{2} \rightarrow 2 \mathrm{C}_{2} \mathrm{H}_{6}+2 \mathrm{H}_{2} \mathrm{O}$

Non-selective oxidation of the $\mathrm{CH}_{3}$ radical may proceed through the following reaction $[13,16]$ :

$\mathrm{CH}_{3}+\mathrm{O}_{2} \rightarrow \mathrm{HCHO}+\mathrm{OH}$

The formaldehyde thus formed gives rise to the formation of $\mathrm{CO}$.

This reaction sequence probably also takes place in the presence of a $\mathrm{Li} /$ $\mathrm{MgO}$ catalyst, however, the catalysed reactions show higher $\mathrm{C}_{2}$ selectivities than is found in the absence of a $\mathrm{Li} / \mathrm{MgO}$ catalyst [16,17]. This is probably caused by the fact that the initiation reaction (13) is much faster in the presence of a $\mathrm{Li} / \mathrm{MgO}$ catalyst than in exclusively gas-phase reactions. This gives rise to a relatively high rate of formation of $\mathrm{CH}_{3}$ and $\mathrm{HO}_{2}$ radicals. One $\mathrm{HO}_{2}$ radical will give rise to the formation of three $\mathrm{CH}_{3}$ radicals through the (rapid) reactions (14)-(16). A high rate of production of $\mathrm{HO}_{2}$ radicals thus gives rise to a high concentration of $\mathrm{CH}_{3}$ radicals. The coupling reaction (9) is more favoured by a high concentration of $\mathrm{CH}_{3}$ radicals than is the oxidation reaction (18), resulting in a higher rate of $\mathrm{C}_{2} \mathrm{H}_{6}$ formation in the case of a $\mathrm{Li} / \mathrm{MgO}$ catalyst than in the absence of this catalyst. It will be shown in a subsequent publication [10] that $\mathrm{CO}$ and $\mathrm{CO}_{2}$ are formed predominantly form $\mathrm{C}_{2} \mathrm{H}_{4}$ (in the presence of a $\mathrm{Li} / \mathrm{MgO}$ catalyst) and the rate of reaction (18) is therefore negligible in the reaction sequence taking place in the presence of a $\mathrm{Li} / \mathrm{MgO}$ catalyst.

Ethylene is formed from the ethane formed in reaction (9) by (oxidative) dehydrogenation reactions. These reactions may take place in the gas phase 
[16]; however, the $\mathrm{Li} / \mathrm{MgO}$ catalyst is also active for this dehydrogenation step [9]

The di-atomic oxygen species with takes part in reaction (13) is possibly a peroxide species; a similar suggestion was made by Otsuka et al. $[7,8]$. The peroxidic surface oxygen species may be stabilized on the surface by the presence of neighbouring carbonate groups; such a stabilization effect has been suggested by Appleby and Nicholson in the case of a molten $\mathrm{Li}_{2} \mathrm{CO}_{3}$ fuel cell $[18]$.

The reaction mechanism presented above is a modification of that proposed by Ito et al. [5]; these workers introduced the basic concept of the formation of $\mathrm{C}_{2} \mathrm{H}_{6}$ through the coupling of $\mathrm{CH}_{3}$ radicals formed by the catalyst (see Introduction). Additional evidence for a mechanism involving $\mathrm{CH}_{3}$ radicals has recently been reported $[1,19-21]$. We therefore believe that this model is correct with respect to the involvement of $\mathrm{CH}_{3}$ radicals (see above). However, our mechanism differs in the suggestion that the rate-limiting step of the reaction sequence is not a dehydroxylation or re-oxidation reaction, as proposed by Ito et al. [5], but the activation of methane by a di-atomic oxygen species, possibly a peroxide species [8].

Our reaction mechanism shows a great resemblance to that proposed by $\mathrm{Ot}$ suka and Jinno for a $\mathrm{Sm}_{2} \mathrm{O}_{3}$ catalyst [7]. The model put forward by these workers is based on kinetic measurements (see Introduction), and includes the same adsorption reactions of oxygen and methane and the same rate-limiting step as suggested in our model (reactions 11-13). It also assumes the formation of $\mathrm{C}_{2} \mathrm{H}_{6}$ through the coupling of $\mathrm{CH}_{3}$ radicals, following the mechanism of Ito et al. [5]. In their kinetic measurements, Otsuka and Jinno [7] did not include the effect of $\mathrm{CO}_{2}$ on the reaction rates. In the case of $\mathrm{Sm}_{2} \mathrm{O}_{3}$, the effect of $\mathrm{CO}_{2}$ is probably less pronounced than with $\mathrm{Li} / \mathrm{MgO}$, as the former material does not form stable surface carbonates under these conditions.

We disagree with both Otsuka et al. [4,7] and Ito et al. [5] in relation to the mechanism of the formation of $\mathrm{CO}$ and $\mathrm{CO}_{2}$. Both sets of authors believe that the formation of $\mathrm{CO}_{x}$ proceeds through the reaction of the $\mathrm{CH}_{3}$ radical with an oxygen species. We believe, however, that total oxidation of $\mathrm{C}_{2} \mathrm{H}_{4}$ is the principal route for the formation of $\mathrm{CO}_{x}$; results supporting this idea are presented in a following publication [10].

\section{CONCLUSIONS}

A kinetic evaluation of the oxidative coupling reaction of methane with oxygen over a $\mathrm{Li} / \mathrm{MgO}$ catalyst at $720^{\circ} \mathrm{C}$ shows:

(i) The reaction rate has a first order dependency on the partial pressure of oxygen $\left(P_{\mathrm{O}_{3}}<11 \mathrm{kPa}\right)$, suggesting that a weakly bonded di-atomic oxygen species is active in the rate determining step under conditions of low oxygen partial pressure. 
(ii) The rate limiting step in the reaction sequence involves reaction between adsorbed methane and oxygen molecules, i.e. the $\mathrm{C}-\mathrm{H}$ bond breaking in the methane molecule. This is in accordance with literature data [15].

(iii) Carbon dioxide acts as a poison for the coupling reaction. The effect of carbon dioxide (and water) on reaction rates has therefore to be taken into account in kinetic evaluations using a $\mathrm{Li} / \mathrm{MgO}$ catalyst.

(iv) A Langmuir-Hinshelwood type mechanism, with competitive adsorption of oxygen and carbon dioxide, applies in this situation. Methane may be adsorbed on the same site or on an adjacent surface site. This results in a reaction mechanism which is in accordance with a model for the formation of the active site which has been presented earlier [12].

(v) The catalytic activation of methane on a Li/MgO catalyst bears a marked resemblance to the gas-phase activation process.

\section{ACKNOWLEDGEMENTS}

S.J.K. thanks the Dutch Foundation for Scientific Research for financial support. We also thank J.A. Vreeman for technical assistance and the NonNuclear Energy programme of the European Community for partial support of the work (Contract No. EN3C-039-NL (GDF)). Finally, we should also like to thank the Salt and Basic Chemicals Division of Akzo for a financial contribution.

\section{REFERENCES}

1 J.A. Sofranko, J.J. Leonard and C.A. Jones, J. Catal, 103 (1987) 302.

2 C.A. Jones, J.J. Leonard and J.A. Sofranko, J. Catal, 103 (1987) 311.

3 W. Bytyn and M. Baerns, Appl, Catal., 28 (1987) 199.

4 K. Otsuka, K. Jinno and A. Morikawa, J. Catal., 100 (1986) 353.

5 T. Ito, J X Wang, C-H Lin and J.H. Lunsford, J. Am. Chem. Soc., 107 (1985) 5062.

6 D.N Olson, V.M. Orera, Y. Chen and M.M. Abraham, Phys. Rev. B, 21 (1980) 1258.

7 K. Otsuka and K. Jinno, Inorg. Chim. Act., 121 (1986) 237.

8 K. Otsuka, A.A. Said, K. Jinno and T. Komatsu, Chem Lett., (1987) 77.

9 J.A. Roos, S.J. Korf, R.H.J. Veehof, J.G. van Ommen and J.R.H. Ross, Catal. Today, 4 (1989) 441.

10 J.A. Roos. S.J. Korf, R.H.J. Veehof, J.G. van Ommen and J.R.H. Ross, Appl. Catal., 52 (1989) 147

11 S.J. Korf, J.A. Roos, N.A. de Bruijn J.G. van Ommen and J.R.H. Ross, J. Chem. Soc., Chem. Commun., (1987) 1433.

12 S.J. Korf, J.A. Roos, N.A. de Bruijn, J.G. van Ommen and J.R.H. Ross, Catal. Today, 2 (1988) 535 .

13 N.N. Semenov, in P.G. Ashmore, F.S. Dainton and T.M. Sugden (Editors), Photochemistry and Reaction Kinetics, Cambridge University Press, London, 1967, p. 229.

14 R.A. Cox, in M.J. Pilling and I.W.M. Smith (Editors), Modern Gas Kinetics, Blackwell Scientific Publications, Oxford, 1987, p. 269. 
15 N.W. Cant, C.A. Lukey, P.F. Nelson and R.J. Tyler, J. Chem. Soc., Chem. Commun., (1988) 766

16 G.S. Lane and E.E. Wolf, J. Catal, 113 (1988) 144.

17 J.A Roos, A.G. Bakker, H. Bosch, J.G. van Ommen and J.R.H. Ross, Catal. Today, 1 (1987) 133

18 A.J Appleby and S. Nicholson, Electroanalytical Chemistry and Interfacial Electrochemistry, 53 (1974) 105.

19 K.D Campbell, E. Morales and J.H. Lunsford, J. Am. Chem. Soc., 109 (1987) 7900.

20 J.H Lunsford, Paper presented at the 196th ACS National Meeting, Division of Fuel Chemistry, Los Angeles (1988).

21 C Mirodatos. Paper presented at the 196th ACS National Meeting, Division of Colloid and Surface Chemistry, Los Angeles (1988). 